\title{
Size- and species-dependent variability in consumption and growth rates of larvae and juveniles of three freshwater fishes
}

\author{
Benjamin H. Letcher, James A. Rice, Larry B. Crowder, and Fred P. Binkowski
}

\begin{abstract}
We tested the hypothesis of no species differences in consumption and growth rates using three species of Lake Michigan fish (yellow perch (Perca flavescens), bloater (Coregonus hoyi), and alewife (Alosa pseudoharengus)), that hatch over a wide range of sizes $(3.5-9.5 \mathrm{~mm})$; Ingestion and growth rates were significantly different among the three species for $10-$ and $20-\mathrm{mm}$ fish, although differences were weaker for $10-\mathrm{mm}$ growth rates. Incorporating these consumption and growth rate estimates and their parameter errors into a simulation model revealed that differences among species in survival could be detected with as few as 3 samples (model runs) for 20-mm fish at both low and high prey density and for $10-\mathrm{mm}$ fish at low prey density, but that 23 samples would be required to detect differences for 10 -mm fish at high prey density. Compared with our 8-h estimates, previous short-term (15-30 min) consumption rate estimates for the same three species overestimated consumption rates for the $20-\mathrm{mm}$ fish but underestimated them for the $10-\mathrm{mm}$ fish. Our results suggest that differences in growth and ingestion among the three species are likely even when fish are $10 \mathrm{~mm}$, but that we may not always be able to detect differences in survival of smaller fish.
\end{abstract}

\begin{abstract}
Résumé : Nous avons vérifié l'hypothèse qu'il n'y avait pas de différences entre les espèces en ce qui a trait aux taux de consommation et de croissance chez trois espèces de poisson du lac Michigan, la perchaude (Perca flavescens), le cisco de fumage (Coregonus hoyi), et le gaspareau (Alosa pseudoharengus), qui, à l'éclosion, présentent une gamme varié de tailles $(3,5$ à $9,5 \mathrm{~mm}$ ). Les taux d'ingestion et de croissance différaient de manière statistiquement significative entre les trois espèces pour les poissons de 10 et $20 \mathrm{~mm}$, bien que les différences étaient moins marquées dans le cas des taux de croissance chez les poissons de $10 \mathrm{~mm}$. L'incorporation de ces valeurs estimées des taux de consommation et de croissance ainsi que des erreurs sur les paramétriques qui les accompagnent dans un modèle a révélé que les différences de survie entre les espèces pouvait être déterminées avec seulement trois échantillons (applications du modèle) pour les poissons de $20 \mathrm{~mm}$ à densité de proies élevée et faible et pour les poissons de $10 \mathrm{~mm}$ à densité de proies faible, mais que 23 échantillons seraient nécessaires pour déceler les différences pour les poissons de $10 \mathrm{~mm}$ à densité de proies élevée. Comparativement à nos valeurs estimées de $8 \mathrm{~h}$, les valeurs estimées antérieures de la consommation à court terme (15-30 min) pour les trois mêmes espèces entraînaient une surestimation des taux de consommation chez les poissons de $20 \mathrm{~mm}$, mais une sous-estimation de ces derniers chez les poissons de $10 \mathrm{~mm}$. Nos résultats laissent entendre que les différences dans la croissance et la consommation chez les trois espèces sont vraisemblablement égales lorsque les poissons ont une longueur de $10 \mathrm{~mm}$, mais que nous ne pourrions pas toujours être en mesure de détecter les différences de survie chez les poissons plus petits. [Traduit par la Rédaction]
\end{abstract}

\section{Introduction}

Small differences in consumption and growth rates can have a substantial impact on survival of larval and juvenile fishes

Received August 31, 1995. Accepted July 16, 1996.

J13061

B.H. Letcher, ${ }^{1}$ J.A. Rice, and L.B. Crowder. ${ }^{2}$ Department of Zoology, Box 7617, North Carolina State University, Raleigh, NC 27695-7617, U.S.A.

F.P. Binkowski. Center for Great Lakes Studies, University of Wisconsin-Milwaukee, 600 East Greenfield Avenue, Milwaukee, WI 53204, U.S.A.

1 Author to whom all correspondence should be sent at the following address: USGS/Biological Resources Division, S.O. Conte Anadromous Fish Research Center, One Migratory Way, P.O. Box 796, Turners Falls, MA 01376, U.S.A. e-mail: bletcher@external.umass.edu

2 Present address: Duke University School of the Environment, Marine Laboratory, 135 Duke Road, Beaufort, NC 28516-9721, U.S.A.
(Houde 1987; Beyer 1989) because many of the factors regulating mortality are size dependent (Blaxter 1986; Anderson 1988; Miller et al. 1988). Because year-class strength and eventually recruitment often are determined by mortality rates while fish are in the larval and juvenile stages (Sissenwine 1984), growth variability during early life can have important population-level consequences (Rice et al. 1993).

Because of the importance of size during the early ontogeny of fishes, researchers have begun to ask recently whether size alone can be used to predict performance of young fish across species. In support of this view, Miller et al. (1988) found that variability in many of the behavioral and energetic processes that may influence survival could be explained by fish length. In further studies, size explained more of the variance in visual acuity and functional responses of larvae and juveniles of three Lake Michigan fishes than did species (Miller et al. 1992, 1993). A size-based approach is attractive because it suggests that generality may exist across species so that we could reasonably predict performance on the basis of size, and that we may be able to use size-based 
estimates as an initial prediction for less well studied species (Miller et al. 1992). Despite the importance of growth during early life, little is known about the relative effects of species and size on growth rate (but see Houde and Schekter 1981). If fish of the same size, but from different species, have very different growth rates under identical conditions, then it will be important to estimate growth for each species individually to predict consumption and growth rates. If, on the other hand, growth rates of different species are similar and scale with body size, specification of size alone should provide adequate growth predictions.

Estimating the variability in growth and consumption among species is also important because it should help in sorting out sources of variability in survival. The potentially large effects of growth rate variability on survival and recruitment (Houde 1987; Rice et al. 1993) suggest that species differences in growth, interacting with size-dependent sources of mortality, could play a part in recruitment variability among species. Species differences, however, will only influence survival if the variability within species is substantially less than the variability among species. Estimating the relative importance of within- and among-species variability in growth rates under controlled conditions may provide data that can be used to determine whether species differences are sufficiently large to contribute to among-species variability in survival.

The goal in this paper was to test the null hypothesis of no species differences in consumption and growth rates for three Lake Michigan fishes, alewife (Alosa pseudoharengus), bloater (Coregonus hoyi), and yellow perch (Perca flavescens), at common lengths over a range of prey densities $\left(0-1000 \cdot \mathrm{L}^{-1}\right)$. We chose these species because they hatch over a broad range of sizes $(3.5-9.5 \mathrm{~mm})$ and because culture techniques are well established (Miller et al. 1992). We conducted the experiments when the fish were identical in length, but at these lengths they varied in age and mass. In the analyses, we controlled for mass by expressing feeding and growth rates as proportions of body mass, but we could not control for age differences. In addition to testing for species effects, we also compared consumption rate predictions from short-term (15-30 min) feeding experiments (Miller et al. 1992) using the same sizes and species with the 8-h estimates obtained as part of this study. With this analysis, we assessed the applicability of short-term functional response estimates to longer-term predictions. Finally, we explored the population-level consequences of our consumption and growth rate variability estimates with a survival simulation model.

\section{Materials and methods}

Experiments were conducted at the Center for Great Lakes Studies, Milwaukee, Wisconsin, during the spring and summer of 1991 and 1992. Ripe females of each of the three species were caught in the field and the embryos were fertilized (alewife, Milwaukee Harbor; bloater, Lake Michigan; yellow perch, Green Bay, Lake Michigan). Eggs were incubated in the laboratory until hatch. On hatching the fish were transferred to 700 - $\mathrm{L}$ fiberglass tanks, where they were raised until the beginning of the trials $(10$ or $20 \mathrm{~mm})$. Water temperatures in the tanks were increased slowly $\left(<1^{\circ} \mathrm{C} \cdot\right.$ day $\left.^{-1}\right)$ to $22^{\circ} \mathrm{C}$ before the $10-\mathrm{mm}$ trials. During rearing, we fed the larvae a mixed assemblage of cultured plankton $(63-425 \mu \mathrm{m})$, Artemia spp. nauplii, commercial fish food (Biodiet starter Nos. 2 and 3), and a ground beef liver mixture $(125-450 \mu \mathrm{m})$ and maintained a $12 \mathrm{~h}$ light : $12 \mathrm{~h}$ dark cycle. Two days before each experiment the fish were fed Artemia spp. nauplii exclusively.

We analyzed consumption and growth rates of each species at initial body sizes of 10 and $20 \mathrm{~mm}$ in 7-day trials. Fish were exposed to five prey density treatments $(0,10,50,250$, and 1000 Artemia spp. nauplii/L), each replicated three times. One day before the beginning of each trial, we selected fish of the appropriate size ( 10 or $20 \mathrm{~mm}$ ) from the rearing tanks and transferred them to the experimental tanks. The tanks were inverted $22-\mathrm{L}$ polycarbonate spring-water bottles that each contained $9 \mathrm{~L}$ of water maintained at $22 \pm 1^{\circ} \mathrm{C}$ by a water bath. Ten fish were placed in each tank in the $10-\mathrm{mm}$ size experiments and five fish were added to each tank in the $20-\mathrm{mm}$ experiments. Ten to 25 fish were also subsampled from the 700-L stock tanks for initial length and mass measurements.

Artemia nauplii tend to sink in fresh water. We used a nauplii resuspension system (Letcher 1994) to maintain an even distribution of nauplii in the tanks during the course of each 8-h feeding period. Blowing air across the surface of the water along the edge of an inverted spring-water bottle created a weak circulation that pushed sinking nauplii to the center of the bottle where they were resuspended by rising air and water. With this method, it appeared that we achieved an even distribution of nauplii with minimal disturbance to the fish.

Because feeding rate was one of our response variables and may be a function of prey density, species, or fish size, we needed to keep densities, an independent variable, as constant as possible. During trials, we replenished prey densities every $2 \mathrm{~h}$ after estimating prey depletion during the previous $2 \mathrm{~h}$ by counting the prey with an image analyzer (details below). This approach was sensitive to changes in fish consumption rates, provided good estimates of daily feeding, and replenished Artemia spp., which tend to die in fresh water after $6 \mathrm{~h}$. The number of prey eaten in each tank was estimated every 2 $h$ by subtracting the estimated number of prey in the tank after $2 \mathrm{~h}$ of feeding from the estimated number at the beginning of each $2-h$ period. Prey were sampled in duplicate at the end of each $2-\mathrm{h}$ period. To calculate the number of nauplii in each tank, the volume removed was measured with a graduated cylinder (average volume $=0.26$ L) and the count was divided by that volume to yield number per litre. To maintain prey densities at average nominal levels, densities in each tank were corrected at the end of each 2-h feeding period using the following equation: number added $=\frac{\mathrm{ATE}}{2}+(\mathrm{NOM}-\mathrm{SAMPLE})$

where number added equaled the number of nauplii to add at the beginning of the next 2 -h period, ATE equaled the number eaten in the previous 2 -h period, NOM was the nominal density $\left((9 \mathrm{~L})^{-1}\right)$, and SAMPLE was the number sampled $\left((9 \mathrm{~L})^{-1}\right)$ at the end of the $2-\mathrm{h}$ feeding period. Because fish in the $20-\mathrm{mm}$ experiments could totally deplete prey in less than $2 \mathrm{~h}$ in the 10 and $50 \cdot \mathrm{L}^{-1}$ treatments, feedings were supplemented $1 \mathrm{~h}$ into each feeding period (after counting with the image analyzer) for those two treatments.

We added the correct number of nauplii by counting individual nauplii with an image analyzer ( 10 and $50 \cdot \mathrm{L}^{-1}$ treatments) or by adding the appropriate volume of known-density nauplii stock ( 250 and $1000 \cdot \mathrm{L}^{-1}$ treatments), using PcVisions + frame grabber board with Java software (Jandel Scientific). Images for analysis were obtained with a video camera (Panasonic WV-S050 system with WV-5000 camera) aimed at the counting bowl (details in Letcher 1994). The density of the nauplii stock was established each day from the mean of 11 samples $(0.25-1 \mathrm{~mL}$ each). The coefficient of variation of the samples was never above $4 \%$ and was usually between 1 and 3\%. There was a good relationship between actual counts (counted under a microscope) and image analyzer counts up 
to about 400 nauplii (actual $=1.2+0.99 \times$ image analyzer, $r^{2}=$ $0.98, n=8$ ).

To count the uneaten nauplii at the end of each day of feeding ( $8 \mathrm{~h}$ total) and to replace water, $7 \mathrm{~L}$ of water was siphoned from each tank and the nauplii were collected on a sieve. We assumed that any nauplii remaining in the tanks were eaten during the next day. The collected nauplii were counted (by eye under a microscope because of contamination with feces and detritus) and were subtracted from the total number added that day (minus the estimated number of nauplii remaining after siphoning) to yield a daily estimate of the number of nauplii eaten.

Individual fish were measured in length (total length) and mass (wet and dry) for estimates of growth. Lengths were taken with an ocular micrometer $( \pm 0.1 \mathrm{~mm})$ in a microscope for fish $<25$ $\mathrm{mm}$ and with ruler for fish $>25 \mathrm{~mm}( \pm 0.2 \mathrm{~mm})$. After removing excess water with absorbent paper, we measured individual wet masses on a Mettler balance $( \pm 0.01 \mathrm{mg})$ and weighed dried fish $\left(>24 \mathrm{~h}\right.$ at $\left.60^{\circ} \mathrm{C}\right)$ on a Cahn microbalance $( \pm 1 \mu \mathrm{g})$. Because there was substantial mortality of fish in the $0 \cdot \mathrm{L}^{-1}$ treatment before the end of the trials, they were removed and measured once $50 \%$ of the fish in each tank had died.

\section{Data analysis}

We could not standardize for all of the differences among species (age, mass, length, developmental stage) in a single experiment; we chose to conduct experiments at identical lengths. We compared among species of a particular length to ask whether there were length-dependent species differences. If the variability within species was similar to that among species and there were no differences among species at a given length, we could conclude that length alone was sufficient to describe feeding or growth rates. If, conversely, there were species differences at a given length, we needed to test for the effect of the other measure of size: mass (which differed among species at a given length). We did this by expressing the dependent variables (consumption and growth rate) as a proportion of mean fish body mass during a trial. If there were no differences among species after we removed the effect of mass, we could conclude that we were unable to reject the null hypothesis of no species differences and that size alone (length and (or) mass) reasonably predicted feeding and growth rates.

We calculated actual prey densities for each tank as the average prey density during the 7 days of a trial. Average daily prey density equaled the mean of the eight daily prey density estimates (data points in Fig. 1). To standardize for mass differences among the species during each experiment, we expressed relative growth $(g$, milligrams per milligram per day) and consumption rates ( $i$, milligrams per milligram per day) as proportions of mean body mass during an experiment using equations with a similar form:

$$
g=\frac{\text { mass }_{\text {fin }}-\text { mass }_{\text {init }}}{\left(\left(\text { mass }_{\text {fin }}+\text { mass }_{\text {init }}\right) / 2\right) \cdot 7 \text { days }}
$$

and

$$
i=\frac{\sum_{j}^{7}(\text { mass eaten on day } j) / \mathrm{NF}_{j}}{\left(\left(\text { mass }_{\text {fin }}+\text { mass }_{\text {init }}\right) / 2\right) \cdot 7 \text { days }}
$$

where mass $s_{\text {fin }}$ and mass $s_{\text {init }}$ were the final and initial masses of the fish in each treatment and $\mathrm{NF}_{j}$ equaled the number of fish in the tank on day $j$.

We fit type II functional response curves (Holling 1959) to describe the relationship between number of Artemia spp. eaten per fish per day $(y)$ and actual mean prey density $(x)$ and between ingestion (milligrams per milligram per day) and Artemia density (Proc Nlin, SAS Institute 1989). The form of the equation was

$$
y=\frac{a T_{t} x}{1+a T_{h} x}
$$

Fig. 1. Artemia density fluctuations over time for a typical day of feeding (20-mm alewife experiment, day 4). Tanks were replenished every $2 \mathrm{~h}$. Each line represents a replicate of one of the four prey densities during an actual day of feeding.

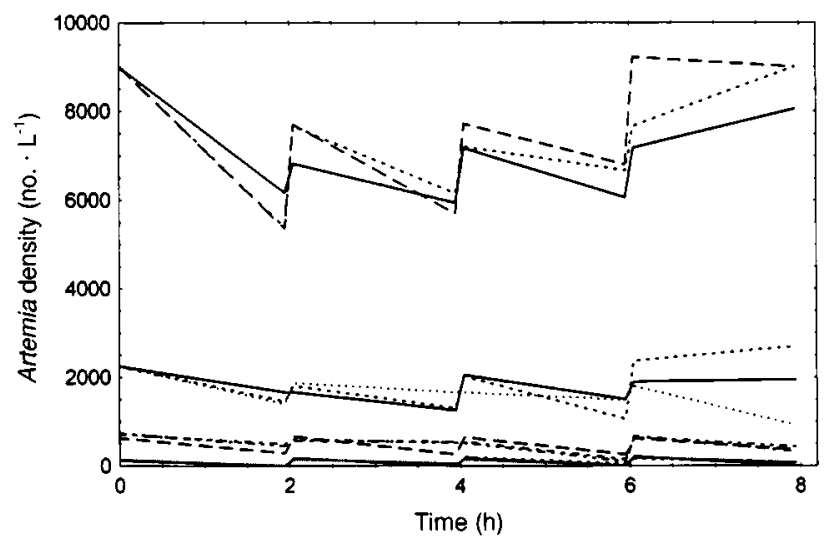

where $a$ and $T_{h}$ were parameters and $T_{t}$ was a constant (the number of seconds during feeding $(8 \mathrm{~h})$ ). Parameter $a$ in eq. 4 represented the instantaneous rate of discovery (attacks per second), and $T_{h}$ was the handling time per prey (seconds).

The relationship between growth ( $y$, milligrams per day or milligrams per milligram per day) and the independent variables prey density or ingestion $(x)$ was expressed as

$$
y=a\left(1-\exp ^{-b x}\right)-c
$$

where $a, b$, and $c$ were parameters. $a-c$ estimated maximum growth rates and $c$ equaled mass loss during starvation when eq. 5 described growth as a function of ingestion. When the relationship between growth and ingestion did not reach an asymptote, we estimated maximum growth from growth at the largest prey density. We calculated maintenance rations (milligrams per milligram per day) by setting $y$ in eq. 5 to zero and solving for $x$.

To test for the effect of species across the range of experimental prey densities, we fit full and reduced nonlinear models (eq. 4 or 5, Ratkowski 1983) to the relationships described above. In this analysis, we compared the error terms of a reduced model, where a regression was fit to data from all three species together, with recombined full models, where the regression was fit to each species separately and the error terms were summed. The summed error terms from the full models gave an estimate of the total error within species, and the reduced model error term was an estimate of the error among species. The difference between these two error terms yielded an estimate of the gain in precision from fitting species separately and was divided by the reduced minus the summed, fullmodel degrees of freedom to give the mean square error (MSE) for the difference. An $F$ test, comparing the difference MSE with the reduced MSE, indicated whether we could reject the null hypothesis of no species differences.

Gross growth efficiency (GGE) equals growth divided by ingestion $(g / i)$ and is useful for comparisons because it standardizes growth per unit ingestion. To compare GGE among species, we calculated mean and maximum GGEs for both experiments. We did not report GGE statistics because they were identical to those of the growth versus relative ingestion $(g-i)$ curves. In the $10-\mathrm{mm}$ experiment, maximum GGE equaled the slope of the $g-i$ curve where a straight line with origin zero was tangent to the curve (calculated as the value of $i$ where the derivative of the GGE versus $i$ curve $=0$ ). Because maximum GGE was not at an intermediate relative ingestion value for the $20-\mathrm{mm}$ fish, we reported maximum GGE for 
Table 1. Initial conditions (mean $\pm S D)$ for each species and experiment.

\begin{tabular}{lcccccr}
\hline & $\begin{array}{c}\text { Hatch length } \\
(\mathrm{mm})\end{array}$ & $\begin{array}{c}\text { Nominal } \\
\text { length }\end{array}$ & $n$ & $\begin{array}{c}\text { Actual length } \\
(\mathrm{mm})\end{array}$ & $\begin{array}{c}\text { Initial mass } \\
(\mathrm{mg} \text { dry })\end{array}$ & Age (days) \\
\hline Alewife & $3.9 \pm 0.45$ & 10 & 13 & $10.6 \pm 1.2$ & $0.33 \pm 0.10$ & 13 \\
& & 20 & 24 & $20.9 \pm 0.72$ & $5.69 \pm 0.91$ & 28 \\
Bloater & $9.26 \pm 0.28$ & 10 & 21 & $10.4 \pm 0.32$ & $0.90 \pm 0.11$ & 3 \\
& & 20 & 24 & $19.9 \pm 0.88$ & $4.19 \pm 0.77$ & 28 \\
Yellow perch & $5.93 \pm 0.21$ & 10 & 24 & $10.0 \pm 0.72$ & $0.87 \pm 0.27$ & 18 \\
& & 20 & 24 & $18.6 \pm 0.93$ & $8.03 \pm 1.47$ & 41 \\
\hline
\end{tabular}

Table 2. Nominal and actual prey densities (no. $\cdot \mathrm{L}^{-1}$ ).

\begin{tabular}{ccccccccc}
\hline & \multicolumn{2}{c}{ Alewife } & & \multicolumn{2}{c}{ Bloater } & & \multicolumn{2}{c}{ Yellow perch } \\
\cline { 2 - 3 } \cline { 8 - 9 } $\begin{array}{c}\text { Nominal } \\
\text { treatment }\end{array}$ & $10 \mathrm{~mm}$ & $20 \mathrm{~mm}$ & & $10 \mathrm{~mm}$ & $20 \mathrm{~mm}$ & & $10 \mathrm{~mm}$ & $20 \mathrm{~mm}$ \\
\hline 10 & $10.8 \pm 0.4$ & $24.3 \pm 0.1$ & & $9.6 \pm 0.4$ & $20.5 \pm 0.5$ & & $13.7 \pm 0.6$ & $19.0 \pm 0.3$ \\
50 & $53.2 \pm 1.9$ & $81.0 \pm 0.0$ & & $54.3 \pm 3.2$ & $77.2 \pm 4.3$ & & $45.9 \pm 0.7$ & $77.5 \pm 1.6$ \\
250 & $253.2 \pm 8.9$ & $233.3 \pm 8.9$ & & $262.6 \pm 5.4$ & $248.9 \pm 3.7$ & & $232.2 \pm 3.8$ & $222.0 \pm 5.5$ \\
1000 & $1018.1 \pm 28.9$ & $1028.7 \pm 17.0$ & & $1044.4 \pm 17.1$ & $995.7 \pm 31.0$ & & $992.3 \pm 16.2$ & $964.1 \pm 15.2$ \\
\hline
\end{tabular}

Note: Values are means \pm SD from the 7-day average prey density of the three replicates. Means for each tank were determined daily from the eight density estimates as shown in Fig. 1.

the $20-\mathrm{mm}$ experiments from the feeding level treatment with the highest average GGE.

To compare short-term (15-30 min, Miller et al. 1992) with longer term $(8 \mathrm{~h}$, this experiment) functional response predictions, we calculated the number of Artemia spp. that a fish would eat in $8 \mathrm{~h}$ from the short-term estimate and compared this with the actual number eaten in $8 \mathrm{~h}$. The actual 8 -h value was from the $1 \mathrm{st}$ day of each trial in the experiment described here, when the sizes in the two experiments were the most similar. Miller et al. (1992) conducted 15- and 30-min functional response experiments with the same species and sizes, and in the same laboratory as reported here. In addition to the duration of the trials, the consumption rate estimation methods also differed between Miller et al. (1993) and the results reported here. We measured depletion rates of the prey as the fish fed, while Miller et al. (1993) examined gut contents. Aside from the methodological differences, the major difference between the two studies is that fish feeding for $8 \mathrm{~h}$ must also digest and process the prey, while fish feeding for 15 or 30 min likely did not have enough time to process what they ate. This analysis allowed us to assess the applicability of short-term feeding estimates to a full day of feeding.

Finally, we addressed whether it was possible to detect species differences in survival by incorporating the parameter errors from the laboratory-derived ingestion and growth functions into a version of an individual-based growth and survival model (Letcher et al. 1996). With the model, we tracked the feeding, growth, and survival of individual fish that could die from either predation or starvation. During runs, fish growth was calculated from ingestion rates estimated by the functional responses at two prey densities $\left(10\right.$ and $\left.250 \cdot \mathrm{L}^{-1}\right)$. Model runs lasted 7 days and started with 100 fish. Prey were encountered randomly by individual fish (from a Poisson distribution) and both predation (60-mm fish predator) and starvation were size dependent (see Letcher et al. 1996 for details).

Parameter estimates for individual fish were drawn from a normal distribution using means and errors from the ingestion and growth functions. Because the parameters were highly correlated, fish were only allowed combinations of parameters that yielded an $r^{2}$ greater than 0.9 for each function. Values of $r^{2}$ were estimated from equa- tions (second-order quadratics) relating the error sums of squares to each function's parameter values. With this approach, we avoided parameter combinations yielding unrealistic values.

With the model, we tested how species differences in survival varied with fish size $(10$ versus $20 \mathrm{~mm})$, prey density (10 and $250 \cdot \mathrm{L}^{-1}$ ), and number of samples (replicate runs, 3-25). By analyzing increasing numbers of runs, we asked how many samples would be required to detect species differences for small and large fish at low and high prey density.

\section{Results}

Actual initial lengths in the experiments were $\pm 1 \mathrm{~mm}$ of target lengths, except for 20 -mm yellow perch, which averaged $18.6 \mathrm{~mm}$ (Table 1). Bloater and yellow perch $10-\mathrm{mm}$ initial masses were similar, and about three times heavier than alewife 10 -mm mass (Table 1). Ten-millimetre bloater were the youngest ( 3 days old) and $10-\mathrm{mm}$ alewife and yellow perch were older (13 and 18 days old, respectively). Twenty-millimetre yellow perch were heaviest and alewife and bloater were 71 and $52 \%$ as heavy, respectively. Twentymillimetre alewife and bloater were both younger (28 days old) than 20-mm yellow perch (41 days old).

During trials, prey densities fluctuated as the prey were eaten and replenished; for most trials the actual daily average prey densities were maintained within $25 \%$ of nominal (Fig. 1; Table 2). Food was always available for fish in the 250 and $1000 \cdot \mathrm{L}^{-1}$ treatments but was depleted occasionally between feedings in the $50 \cdot \mathrm{L}^{-1}$ treatment, and usually in the $10 \cdot \mathrm{L}^{-1}$ treatment (Fig. 1), although never for $>1 \mathrm{~h}$. Owing to attempts to maintain prey densities, calculated actual densities (Table 2) were about twice the nominal value for the $20-\mathrm{mm}$ fish in the 10 and $50 \cdot \mathrm{L}^{-1}$ treatments. Analyses below used actual prey densities.

The functional responses for each experiment were described well by the type II functional response equation 
Table 3. Functional response parameters $\left(a, T_{h}\right.$, see eq. 4, Fig. 2) with associated $r^{2}$, and maximum consumption rate from this experiment.

\begin{tabular}{|c|c|c|c|c|c|c|c|}
\hline & $\begin{array}{l}\text { Length } \\
(\mathrm{mm})\end{array}$ & $r^{2}$ & $\begin{array}{c}a \pm \mathrm{SE} \\
\left(\mathrm{s}^{-1} \times 10^{-4}\right)\end{array}$ & $\begin{array}{c}T_{h} \pm \mathrm{SE} \\
\text { (s) }\end{array}$ & $\begin{array}{c}C_{\max } \\
\left(\mathrm{mg} \mathrm{mg}^{-1} \text { day }^{-1}\right)\end{array}$ & $\begin{array}{l}\text { No. eaten } \\
\left((8 \mathrm{~h})^{-1}\right) \\
\text { at } 1000 \\
\text { prey/L }\end{array}$ & $\begin{array}{c}\text { No. eaten } \\
\left((8 \mathrm{~h})^{-1}\right) \\
\text { predicted from } \\
\text { 15-min experiment }\end{array}$ \\
\hline \multirow[t]{2}{*}{ Alewife } & 10 & 0.94 & $1.05 \pm 0.35$ & $33.74 \pm 5.69$ & 1.89 & 706.6 & 285.9 \\
\hline & 20 & 0.99 & $5.96 \pm 0.92$ & $24.09 \pm 1.24$ & 0.204 & 1160.4 & 7454.3 \\
\hline \multirow[t]{2}{*}{ Yellow perch } & 10 & 0.98 & $2.53 \pm 0.56$ & $54.66 \pm 3.81$ & 0.558 & 535.4 & 333.7 \\
\hline & 20 & 0.99 & $8.52 \pm 1.24$ & $10.93 \pm 0.62$ & 0.296 & 1854.2 & 8738.1 \\
\hline
\end{tabular}

Note: The last two columns contain a comparison of actual 8-h consumption rates at 1000 prey/L on day 1 of the experiments presented in this paper and predicted 8-h consumption rates from 15-min functional response experiments (Miller et al. 1992).

(eq. 2; Table 3, $r^{2}$ range of $0.94-0.99$ ). The attack constant, $a$, was consistently higher for the larger fish and ranged from about 1 to $2.5 \cdot \mathrm{s}^{-1}$ for $10-\mathrm{mm}$ fish and from about 6 to $8.5 \cdot \mathrm{s}^{-1}$ for 20-mm fish (Table 3). Within a species, handling times $\left(T_{h}\right)$ were always shorter for the larger fish. Ten-millimetre fish required from 23 to $55 \mathrm{~s}$ to handle an Artemia nauplius, while the larger 20-mm fish took 11-24 s/prey (Table 3). While the number of Artemia spp. eaten per $8 \mathrm{~h}$ was similar among the species at low prey densities, there were significant differences among species across all prey densities for both 10-mm fish ( $p=0.011$, Fig. 2 ) and 20-mm fish ( $p=$ 0.0002 , Fig. 2). Twenty-millimetre yellow perch ate the most Artemia spp. at all prey densities and alewife ate the least.

When consumption rates were calculated per unit fish mass (relative ingestion), the differences among species were exaggerated $(p=0.00045,10 \mathrm{~mm} ; p=0.00017,20 \mathrm{~mm})$ relative to calculations using numbers eaten, indicating that functional response differences among species could not be explained by differences in fish masses. Maximum consumption ranged from 20 to $189 \%$ body weight day ${ }^{-1}$ (Table 3 ).

Comparison of predicted 8-h feeding rates from short-term functional response estimates (15-30 min, Miller et al. 1992) with longer term $(8 \mathrm{~h})$ consumption rates revealed that the short-term functional response experiments underestimated by about $33-75 \%$ the number actually eaten in $8 \mathrm{~h}$ by the $10-$ $\mathrm{mm}$ fish, but overestimated by four- to six-fold the number eaten by $20-\mathrm{mm}$ fish (Table 3 ). This suggests that smaller $10-\mathrm{mm}$ fish can maintain and exceed short-term feeding rate estimates during a full $8 \mathrm{~h}$ of feeding, while larger $20-\mathrm{mm}$ fish cannot.

There were significant absolute growth rate differences among species for both the 10- and 20-mm fish ( $p<0.0001$, Fig. 3). Growth increased rapidly at low prey densities and reached a plateau at the $250 \cdot \mathrm{L}^{-1}$ treatment in most cases (Fig. 3). For both lengths, yellow perch grew the fastest at most prey densities. The growth rates of alewife and bloater were similar at $10 \mathrm{~mm}$, while $20-\mathrm{mm}$ alewife grew faster than $20-\mathrm{mm}$ bloater. The magnitude of the species effect was similar ( $p<0.0001$ ) when the effect of mass was removed by expressing growth rates as a proportion of body mass (Fig. 4). Bloaters consistently grew more slowly at high prey densities than both alewife and yellow perch.
Fig. 2. Functional responses for the six experiments. Each point represents the mean value $( \pm \mathrm{SE})$ of an individual tank. The $p$ values are from the full-reduced nonlinear test of the null hypothesis of no species differences in functional responses. Parameter values are in the Appendix and error bars were omitted for lower prey densities for clarity.
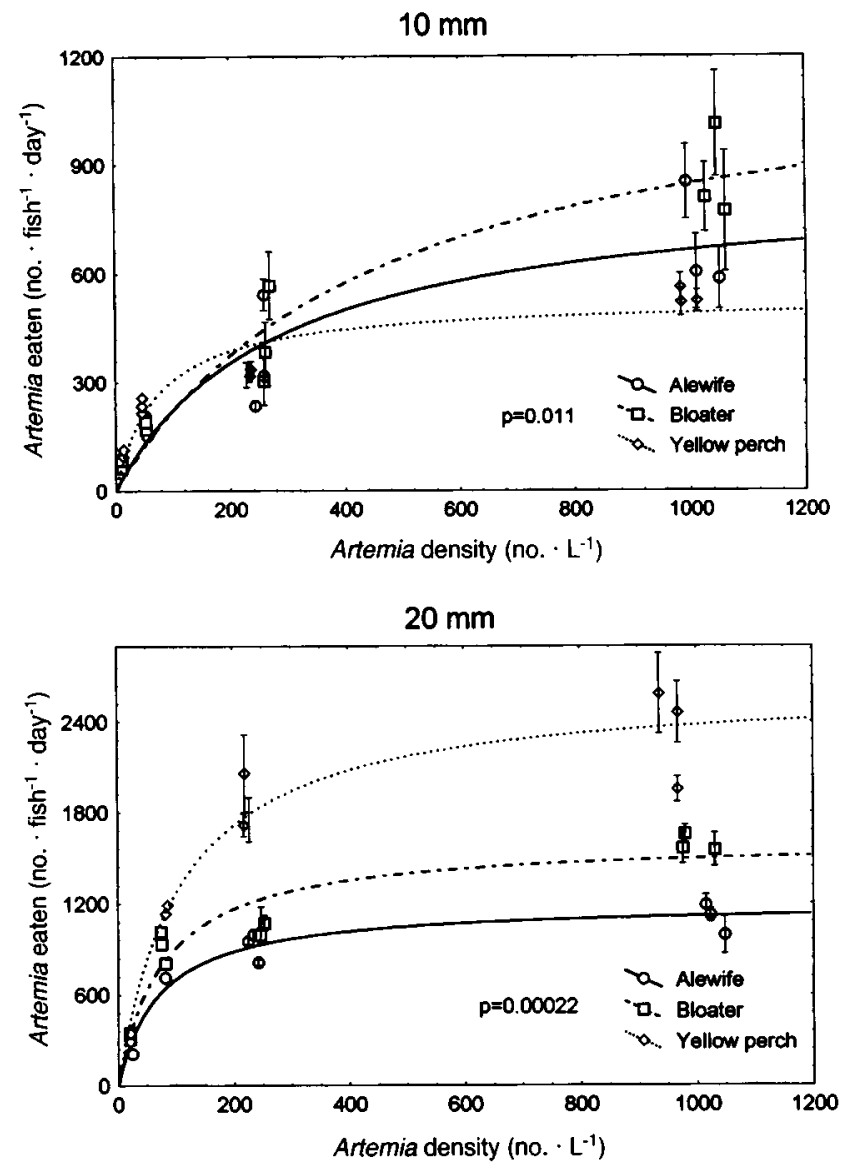

Plotting relative growth versus relative ingestion removes the effect of prey density (and fish mass) and shows the relationship between food consumed and growth. There were significant differences among species, although differences 
Fig. 3. Absolute growth rates (means $\pm \mathrm{SE}$ ) as a function of prey density for the six experiments. The $p$ values are from the full-reduced nonlinear test of the null hypothesis of no species differences in growth rates.

$10 \mathrm{~mm}$
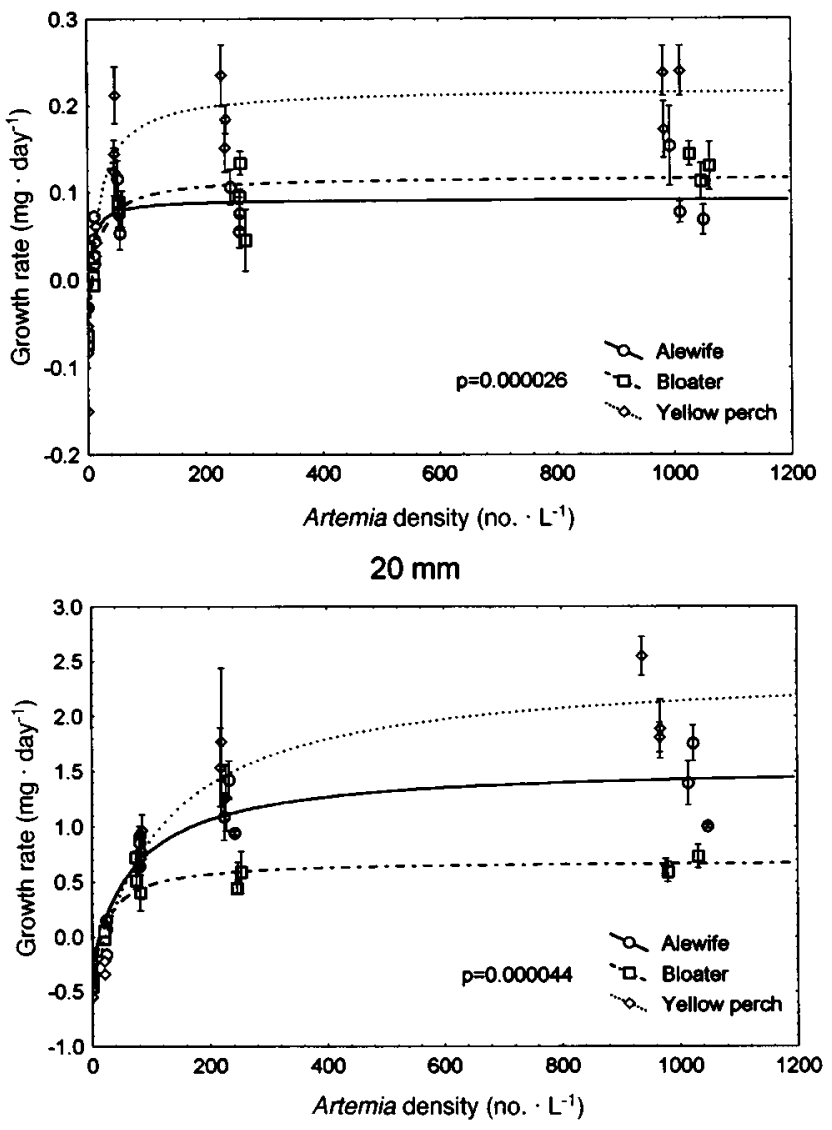

were weaker for $10-\mathrm{mm}$ fish (Fig. $5, p=0.021$ ) than for 20-mm fish (Fig. 5, $p=0.0006$ ). Ten-millilitre bloater grew the slowest per unit ingestion, especially at higher ingestion rates, while alewife and yellow perch grew at similar rates. Twenty-millilitre alewife grew from approximately 0.05 to $0.07 \cdot$ day $^{-1}$ faster than did bloater or yellow perch.

The $g-i$ curves for the $10-\mathrm{mm}$ fish flattened at high ingestion rates, which is typical for larval fish (Kiorboe et al. 1987; Letcher and Bengtson 1993a), but the curves of the 20$\mathrm{mm}$ fish were linear (alewife and yellow perch) or slightly decelerating (bloater) over the range of ingestion rates observed (Fig. 5). It is unlikely that fish were limited by prey density, which would have limited ingestion rates and the possibility of maximum growth rate, because food was constantly available during the 8 -h feeding periods at the two higher feeding levels $\left(250\right.$ and $\left.1000 \cdot \mathrm{L}^{-1}\right)$. The differences in curve shape may be related to developmental stage; both the 20-mm alewife and yellow perch were near metamorphosis (Auer 1982; B.H. Letcher, personal observation), the period of development when gut morphology changes rapidly.

Mean and maximum GGEs of the $20-\mathrm{mm}$ fish were about twofold greater than those of the $10-\mathrm{mm}$ fish (Table 4). Alewife consistently had the highest mean GGEs (average =
Fig. 4. Relative growth rates (means $\pm S E$ ) as a function of prey density for the six experiments. The $p$ values are from the full-reduced nonlinear test of the null hypothesis of no species differences in growth rates.

$10 \mathrm{~mm}$
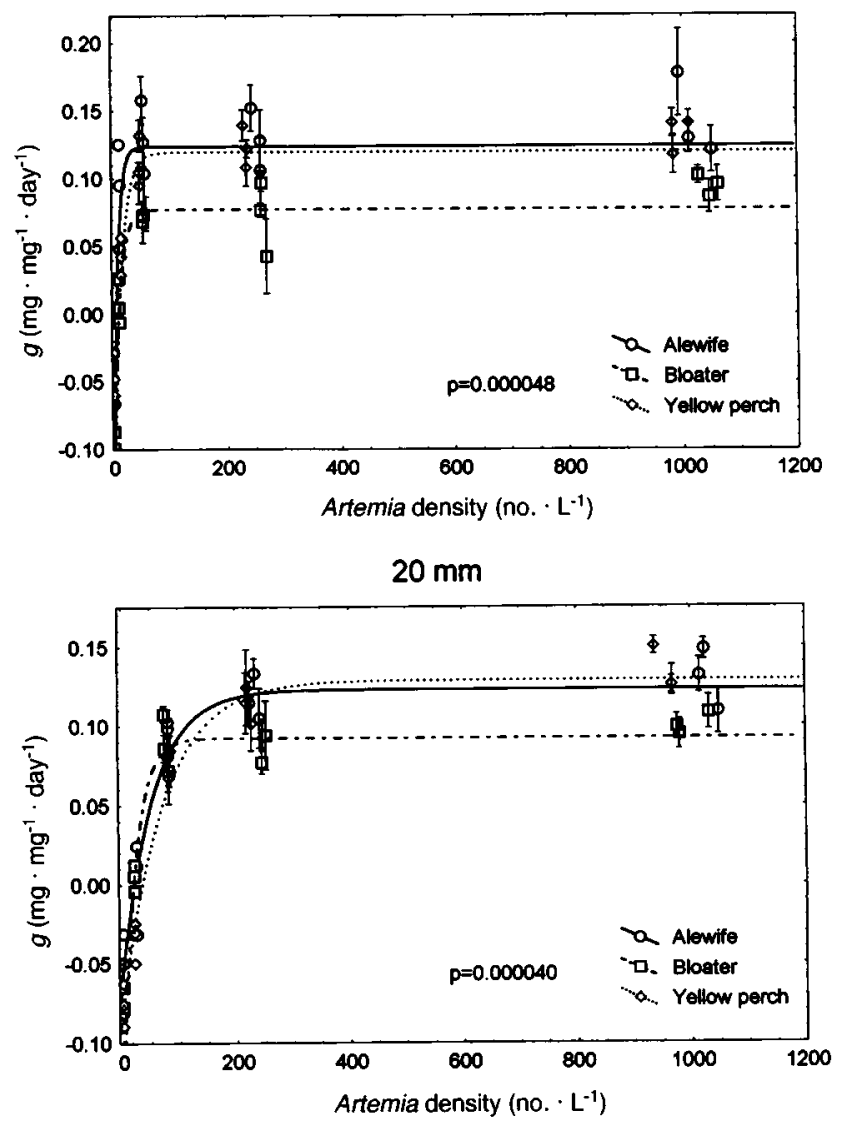

0.25 ), bloater's was lower (average $=0.15$ ), and the average maximum GGE of yellow perch was intermediate (average $=0.19$ ) (Table 4). Overall, alewife converted food to body mass most efficiently, while bloater were the least efficient.

With our model simulations, we tested the effects of fish size, prey density, and number of samples on our ability to detect differences in survival among species. There were significant differences among species $(p<0.001$, one-way ANOVA) for both prey densities $\left(10\right.$ and $\left.250 \cdot \mathrm{L}^{-1}\right)$ and all number of samples (3-25) for $20-\mathrm{mm}$ fish, suggesting that species differences in ingestion and growth rates are very likely to translate into differences in survival for $20-\mathrm{mm}$ fish. In contrast, there was an interaction between prey density and number of samples for the 10-mm fish; significant differences $(p<0.05)$ in survival among species occurred with fewer samples $(<3, p$ value $=0.038-0.002$ (number of samples), $p<0.002$ ) for fish at 10 prey $/ \mathrm{L}$, while 23 samples were required for fish at $250 \mathrm{prey} / \mathrm{L}$ ( $p$ value $=0.605-$ 0.025 (number of samples), $p<0.0001$ ). Overall, model results suggest that we are likely to find species differences in survival for $20-\mathrm{mm}$ fish and for $10-\mathrm{mm}$ fish at low prey densities, but that species differences will be difficult to detect for $10-\mathrm{mm}$ fish at higher prey densities. 
Table 4. Growth and consumption rate data for the six experiments.

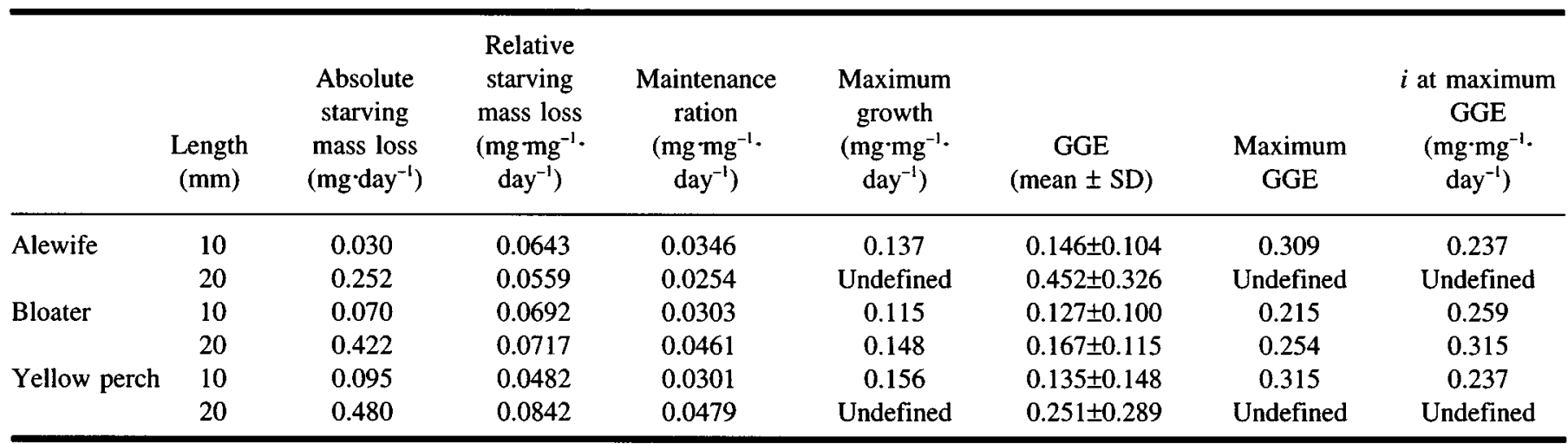

Note: Starving mass loss $\left(\mathrm{mg}^{\mathrm{day}}{ }^{-1}\right)$ is the absolute mass loss per day and relative starving mass loss $\left(\mathrm{mg} \cdot \mathrm{mg}^{-1} \cdot\right.$ day $\left.^{-1}\right)$ equals $c$ in eq. 5 . Maximum growth was estimated as $a-c$ from eq. 5 (undefined when the function did not asymptote over the range of data), and maintenance ration is the proportion of body mass required to maintain constant body mass. Mean GGE was calculated over all treatments; maximum GGE represents the greatest predicted GGE for each experiment and ingestion (i) at maximum GGE is the relative daily consumption rate required to give maximum GGE.

Fig. 5. Relative growth rates (means $\pm \mathrm{SE}$ ) as a function of relative ingestion rates for the six experiments. The $p$ values are from the full-reduced nonlinear test of the null hypothesis of no species differences in the $g-i$ relationship.
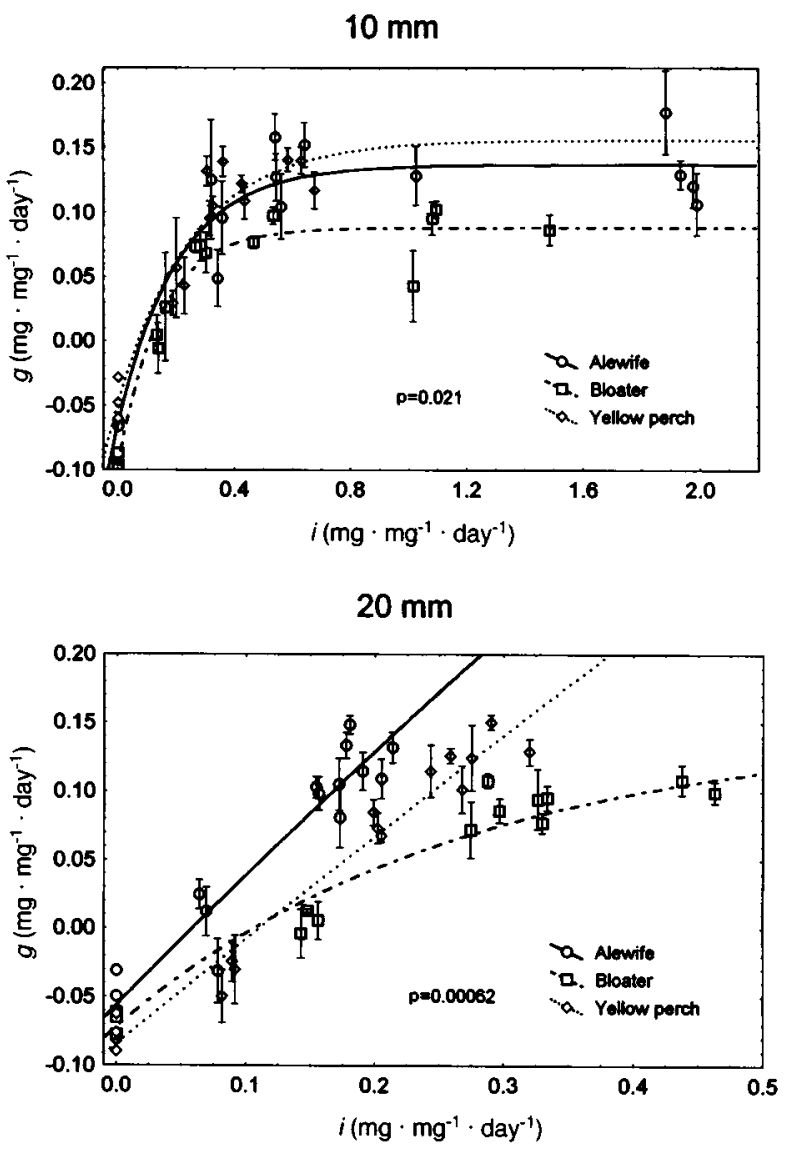

\section{Discussion}

We investigated the effects of species and size on ingestion and growth rates for three species of Lake Michigan fish that hatch over a broad range of sizes $(3.5-9.5 \mathrm{~mm}$ ). Our null hypothesis was that species differences would have no effect on ingestion and growth rates for fish of similar sizes. Growth and ingestion rates were significantly different for both 10- and 20-mm fish, although differences among species were stronger for the larger fish. Incorporating the growth and ingestion relationships and their parameter errors into a population simulation model demonstrated that we are likely to detect species differences in survival for $20-\mathrm{mm}$ fish, but that detecting differences for $10-\mathrm{mm}$ fish at high prey density would require an unrealistically high number of samples $(>23)$. Thus, while there may be size-based differences among small fish that are generalizable across taxa (Miller et al. 1988; Houde 1989; Houde and Zastrow 1993), differences among species will contribute to a large part of the variability in survival among species, especially for fish $>10 \mathrm{~mm}$ (Houde and Schekter 1980, 1981).

Small differences in growth among populations (Conover 1990), cohorts (Leak and Houde 1987; Kneib 1993), or individuals (Rosenberg and Haugen 1982; Rice et al. 1993; Rose and Cowan 1993) within a species are more likely to obscure species differences when fish are $<10 \mathrm{~mm}$ than when they are larger. As fish approach metamorphosis, species differences become more pronounced (Fig. 5). Investigating the effects of variability in growth within species for small fish $(<10$ $\mathrm{mm})$ and both within and among species for larger fish $(>20$ $\mathrm{mm}$ ) may lead to insights about processes that control survival during early life history. In general, differences among freshwater larvae, which are larger at hatch, may be more pronounced than differences among marine larvae (Houde 1994).

Estimates of species effects derived under identical conditions in the laboratory may be conservative relative to differences that could exist in the field. Species differences in nature may be magnified because the fish in this study could not choose habitat or prey types. The differences among species observed in this study represent alternative physiologies and bioenergetics, and possibly not the full range of among-species variability because behavioral and habitat choices were constrained.

Alternatively, species performance (consumption and growth rates) could converge in nature if the full range of behavioral and habitat choices were available. For instance, 
different thermal optima among species could result in varying responses. If the thermal optimum for a species is lower than the temperature used here $\left(22^{\circ} \mathrm{C}\right)$, the performance of that species may be compromised by the relatively high temperature. This may have been the case for the bloater, which hatch at lower temperatures $\left(2-4^{\circ} \mathrm{C}\right.$, Wells 1966), although bloater do move into warmer surface waters within 1-2 weeks of hatching. Optimal temperature for food consumption by adult bloater is at least $16.8^{\circ} \mathrm{C}$ (maximum temperature in Binkowski and Rudstam 1994). Alewife and yellow perch, which occupy the littoral zone during early life and therefore typically may encounter slightly higher temperatures and do appear to have higher optimal consumption temperatures $\left(24\right.$ and $29^{\circ} \mathrm{C}$, respectively (Post 1990; Stewart and Binkowski 1986)), grew at similar relative rates as a function of prey density, and both species grew faster than bloater (Fig. 4). The extent to which evaluating species effects at a single temperature affected our conclusions is unknown. In contrast with growth and consumption as functions of prey density, the relationship between relative growth and ingestion does not appear to be affected by temperature (Checkley 1984; Houde 1989; Houde and Zastrow 1993; Letcher and Bengtson 1993a). Differences in thermal optima among species, therefore, may be relatively unimportant in regulating species differences in growth efficiency.

Miller et al. (1992) investigated the size dependence of parameters of the type II functional response curve over a wide range of young-of-year lengths for the same three species used here. They found no significant effect of species on parameter estimates for attack constant and handling time for fish from 10 to $40 \mathrm{~mm}$, but there was a significant effect of size. This contrasts with the results presented here where, within sizes, we found a significant effect of species on functional responses. The different conclusion between the two studies probably reflects differences in statistical design and level of analysis. We were interested in the level of complexity required to predict growth and consumption rates of fish of different sizes. For predictive ability, we found that we needed to include species in our description of consumption rate. Miller et al. (1992) asked questions on a much broader scale (across sizes, not within) and over a wider range of sizes, with the goal of evaluating how much variability in consumption rate parameters could be explained by size and species. Clearly, results depend on the questions asked and on the level of analysis.

The shape of the curves that relate growth to ingestion ( $g-$ $i$ curves) appears to depend on developmental stage. Larval fish had decelerating $g-i$ curves, but fish close to or beyond metamorphosis had linear $g-i$ curves (Fig. 5). Alewife and yellow perch both metamorphose around 19-20 mm (Auer 1982), while bloater metamorphose between 25 and $30 \mathrm{~mm}$ (Auer 1982). The $g-i$ curve for $25-\mathrm{mm}$ yellow perch was also linear (B.H. Letcher, unpublished results). Further, the temperature-corrected summary relationships for many species of larvae reported by Checkley (1984) and Letcher and Bengtson (1993a) also showed decelerating relationships. The decelerating $g-i$ curves of the larval fish suggest that they maximize consumption rate and not efficiency of growth (Checkley 1984). Despite decreasing increments in growth per unit increase in ingestion, larvae maintained rapid ingestion rates at high prey densities. Larvae may have evolved to maximize growth rate over efficiency because of the strongly size-dependent nature of larval mortality (Miller et al. 1988). The larger, metamorphosed fish (20-mm alewife and yellow perch) seemed to consume prey at a rate that maximized conversion efficiency (linear $g-i$ curves, Fig. 5). The conversion efficiencies of juvenile fish may be higher for at least two reasons; ingestion rates of metamorphosed fish may be limited by the development of differentiated guts, and increased digestive efficiency of the older fish (Buckley and Dillmann 1982; Govoni et al. 1982; Klumpp and von Westernhagen 1986) may allow better processing of the meal.

Many functional response estimates in the literature are from short-term feeding experiments (e.g., Miller et al. 1992). This is often the case because trials must be short enough to avoid prey depletion and gut evacuation when feeding rates are estimated from gut contents. These short-term functional response estimates frequently are used to estimate feeding over an entire day of feeding. However, short-term estimates may not be good predictors of full-day ingestion rates if feeding rate is not constant during a whole day of feeding. Comparison between short-term (15-30 min, Miller et al. 1992) feeding rate estimates based on gut contents and the longer term $(8 \mathrm{~h})$ prey depletion estimates presented in this paper revealed that the short-term estimates underestimated full-day feeding rates by $33-75 \%$ for $10-\mathrm{mm}$ larvae, but they overestimated full-day feeding rates by four to six times for 20-mm larvae (Table 3 ). These results are probably related to digestion differences between $10-$ and $20-\mathrm{mm}$ fish. Because the digestive systems of the $20-\mathrm{mm}$ fish had begun to develop into stomachs (alewife and yellow perch had metamorphosed), the larger fish were likely eating meals instead of feeding continuously. Short-term 15- to 30-min trials may measure the rate at which juveniles fill their guts without accounting for the time required for digestive pauses. This would result in elevated short-term ingestion rate estimates relative to the longer term estimates.

The opposite pattern was observed with the $10-\mathrm{mm}$ fish; the short-term estimates underestimated full-day estimates. This suggests that $10-\mathrm{mm}$ larvae were capable of maintaining and even exceeding the short-term feeding rate estimates during a full $8 \mathrm{~h}$ of feeding. High, sustained ingestion rates of larvae are consistent with their gut morphology (tube, no stomach) and a "conveyor-belt approach" to digestion. High ingestion rates of $10-\mathrm{mm}$ larvae are also consistent with the notion that larvae maximize feeding rate (see above). In support of this view, Letcher and Bengtson (1993b) found that 7-day-old larval inland silverside (Menidia beryllina) consumed prey at a constant rate during $12 \mathrm{~h}$ of feeding in the laboratory. These results indicate that adequately predicting full-day feeding rates from short-term functional response experiments may depend on the developmental stage of the fish.

Our results indicate that we will be unlikely to predict growth and consumption rates of the three species we studied on the basis of size alone; species-specific relationships appear to be required. Although differences in growth and consumption rates among species were less pronounced for the $10-\mathrm{mm}$ fish, they were still statistically significant. Simulation model results using the data from this study indicated that species differences in survival may be readily detectable for $20-\mathrm{mm}$ fish, but were not always so for $10-\mathrm{mm}$ fish. Gen- 
erally, it appears that we will not be able to use common, size-dependent relationships to predict growth, consumption, or survival rates for small fish $(<20 \mathrm{~mm})$, although differences in growth and survival among 10 -mm fishes will be more difficult to detect than differences among $20-\mathrm{mm}$ fishes.

\section{Acknowledgments}

We thank Thomas Miller and two anonymous reviewers for constructive comments on the manuscript. This work would not have been possible without the technical assistance of Marsha Jones and Brian Nordskog. Julia Auckland and Elizabeth Priddy tirelessly counted the samples of uneaten brine shrimp nauplii. We thank the staff of The Center for Great Lakes Studies, in particular Chris Ney, Jason Kroll, Dave Meuller, and Steve Yeo, who collected and fertilized the zygotes, often under difficult circumstances, and who raised the fish and kept things running smoothly. This work was funded by the University of Wisconsin Sea Grant Institute under grants from the National Sea Grant College Program, National Oceanic and Atmospheric Administration, U.S. Department of Commerce, and from the State of Wisconsin, Federal grant No. NA90AA-D-SG469, project No. NA-84AA-D-00065, and by an Electric Power Research Institute fellowship to B.H.L.

\section{References}

Anderson, J.T. 1988. A review of size dependent survival during pre-recruit stages of fishes in relation to recruitment. J. Northwest Atl. Fish. Soc. 8: 55-66.

Auer, N.A. 1982. Identification of larval fishes of the Great Lakes basin with emphasis on the Lake Michigan drainage. Special publication 82-3 edition. Great Lakes Fishery Commission, Ann Arbor, Mich.

Beyer, J.E. 1989. Recruitment stability and survival: simple sizespecific theory with examples from the early life dynamics of marine fish. Dana, 7: 45-147.

Blaxter, J.H.S. 1986. Development of sense organs and behaviour of teleost larvae with special reference to feeding and predator avoidance. Trans. Am. Fish. Soc. 115: 98-114.

Binkowski, F.P., and Rudstam, L.G. 1994. Maximum daily ration of Great Lakes bloater. Trans. Am. Fish. Soc. 123: 335-342.

Buckley, L.J., and Dillmann, D.W. 1982. Nitrogen utilization by larval summer flounder Paralichthys dentatus (Linnaeus). J. Exp. Mar. Biol. Ecol. 59: 243-256.

Checkley, D.M. 1984. Relation of growth to ingestion for larvae of Atlantic herring Clupea harengus and other fish. Mar. Ecol. Prog. Ser. 18: 215-224.

Conover, D.O. 1990. The relation between capacity for growth and length of growing season: evidence for and implications of countergradient variation. Trans. Am. Fish. Soc. 119: 416-430.

Govoni, J.J., Peters, D.S., and Merriner, J.V. 1982. Carbon assimilation during larval development of the marine teleost Leiostomus xanthurus Lacepede. J. Exp. Mar. Biol. Ecol. 64: 287-299.

Holling, C.S. 1959. The components of predation as revealed by a study of small mammal predation of the European sawfly. Can. Entomol. 91: 293-332.

Houde, E.D. 1987. Fish early life dynamics and recruitment variability. Am. Fish. Soc. Symp. 2: 17-29.

Houde, E.D. 1989. Comparative growth, mortality, and energetics of marine fish larvae: temperature and implied latitudinal effects. Fish. Bull. 87: 471-495.
Houde, E.D. 1994. Differences between marine and freshwater fish larvae: implications for recruitment. ICES J. Mar. Sci. 51: 91-97.

Houde, E.D., and Schekter, R.C. 1980. Feeding by marine fish larvae: developmental and functional responses. Environ. Biol. Fishes, 5: 315-334.

Houde, E.D., and Schekter, R.C. 1981. Growth rates, rations and cohort consumption of marine fish larvae in relation to prey concentrations. Rapp. P.-V. Reun. Cons. Int. Explor. Mer, 178: 441453.

Houde, E.D., and Zastrow, C.E. 1993. Ecosystem- and taxonspecific dynamic and energetics properties of larval fish assemblages. Bull. Mar. Sci. 53: 290-335.

Kiorboe, T., Munk, P., and Richardson, K. 1987. Respiration and growth of larval herring Clupea harengus: relation between specific dynamic action and growth efficiency. Mar. Ecol. Prog. Ser. 40: $1-10$.

Klumpp, D.W., and von Westernhagen, H. 1986. Nitrogen balance in marine fish larvae: influence of developmental stage and prey density. Mar. Biol. (Berlin), 93: 189-199.

Kneib, R.T. 1993. Growth and mortality in successive cohorts of fish larvae within an estuarine nursery. Mar. Ecol. Prog. Ser. 94: $115-127$.

Leak, J.C., and Houde, E.D. 1987. Cohort growth and survival of bay anchovy Anchoa mitchilli larvae in Biscayne Bay, Florida. Mar. Ecol. Prog. Ser. 37: 109-122.

Letcher, B.H. 1994. Causes and consequences of growth variability in young fishes. Ph.D. dissertation, North Carolina State University, Raleigh, N.C.

Letcher, B.H., and Bengtson, D.A. 1993a. Effects of food density and temperature on feeding and growth of young inland silversides (Menidia beryllina). J. Fish Biol. 43: 671-686.

Letcher, B.H., and Bengtson, D.A. 1993b. Effects of food density on growth and patterns of food consumption by larval silverside fish, Menidia beryllina; a laboratory investigation with image analysis. J. Exp. Mar. Biol. Ecol. 167: 197-213.

Letcher, B.H., Rice, J.A., Crowder, L.B., and Rose, K.A. 1996. Variability in survival of larval fishes: disentangling components with a generalized individual-based model. Can. J. Fish. Aquat. Sci. 53: 787-801.

Miller, T.J., Crowder, L.B., Rice, J.A., and Marschall, E.A. 1988. Larval size and recruitment mechanisms in fishes: toward a conceptual framework. Can. J. Fish. Aquat. Sci. 45: 1657-1670.

Miller, T.J., Crowder, L.B., Rice, J.A., and Binkowski, F.P. 1992. Body size and the ontogeny of the functional response in fishes. Can. J. Fish. Aquat. Sci. 49: 805-812.

Miller, T.J., Crowder, L.B., and Rice, J.A. 1993. Ontogenetic changes in behavioural and histological measures of visual acuity in three species of fish. Environ. Biol. Fishes, 37: 1-8.

Post, J.R. 1990. Metabolic allometry of larval and juvenile yellow perch (Perca flavescens): in situ estimates and bioenergetic models. Can. J. Fish. Aquat. Sci. 47: 554-560.

Ratkowski, D.A. 1983. Nonlinear regression modeling. Marcel Dekker, New York.

Rice, J.A., Miller, T.J., Rose, K.A., Crowder, L.B., Marschall, E.A., Trebitz, A.S., and DeAngelis, D.L. 1993. Growth rate variation and larval survival: inferences from an individual-based sizedependent predation model. Can. J. Fish. Aquat. Sci. 50: 133142.

Rose, K.A., and Cowan, J.H., Jr. 1993. Individual-based model of young-of-the-year striped bass population dynamics. I. Model description and baseline simulations. Trans. Am. Fish. Soc. 122: $415-438$.

Rosenberg, A.A., and Haugen, A.S. 1982. Individual growth and size-selective mortality of larval turbot (Scophthalmus maximus) reared in enclosures. Mar. Biol. (Berlin), 72: 73-77.

SAS Institute. 1989. SAS user's guide, version 6. SAS Institute, Cary, N.C. 
Sissenwine, M.P. 1984. Why do fish populations vary? In Exploitation of marine communities. Edited by R. May. Springer-Verlag, Berlin. pp. 59-94.

Stewart, D.J., and Binkowski, F.P. 1986. Dynamics of consumption and food conversion by Lake Michigan alewives: an energeticsmodeling synthesis. Trans. Am. Fish. Soc. 115: 643-661.
Wells, L. 1966. Seasonal and depth distribution of larval bloater (Coregonus hoyi) in southeastern Lake Michigan. Trans. Am. Fish. Soc. 95: 388-396.

\section{Appendix}

Parameters $( \pm \mathrm{SE})$ for the equations describing feeding and growth relationships (Figs. 2-5).

\section{Alewife}

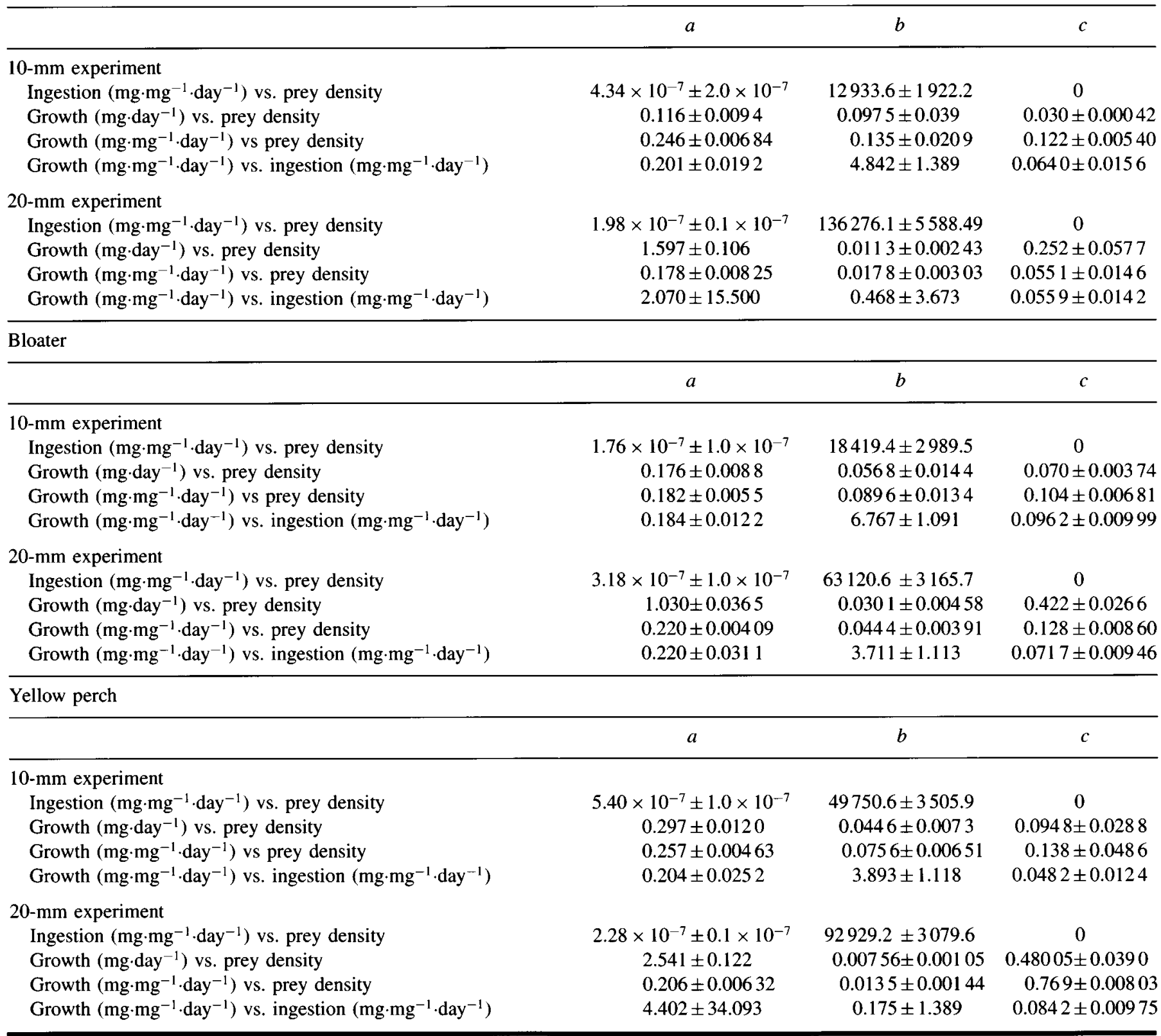

Note: The form of the feeding equations was $y=\frac{a d x}{1+a b x}+c$ where $a, b$, and $c$ were parameters, $x$ was prey density (no. $\cdot \mathrm{L}^{-1}$ ), $y$ was feeding rate ( $\mathrm{mg} \cdot \mathrm{mg}^{-1} \cdot \mathrm{day}^{-1}$ ), and $d$ equaled $8 \times 60 \times 60$ (the number of seconds available for feeding each day). We estimated the effect of prey density and feeding rate growth using $y=a\left(1-\exp ^{-b x}\right)-c$ where $a, b$, and $c$ were parameters (Proc Nlin, SAS Institute 1989). For each species-specific estimate the number of observations equaled 15. Functional response parameters for the 10- and 20-mm experiments are given in Table 3. 